\title{
Holistic governance and Shared cities: new ideas of urban management under the vision of public governance
}

\author{
Rao Huang \\ Yunnan University of Finance and Economics, \\ ,Kunming, P.R.China \\ rh39@qq.com
}

\begin{abstract}
The city offers great opportunities and possibilities for mankind. But the urban problems associated with the rapid development of cities also come together. How to solve these problems is the first problem that city managers need to solve. As the co-governance behavior of multi-subjects, urban governance requires the participation of government, citizens, enterprises, social organizations and community organizations. From the perspective of how to build a humanized city, this paper puts forward a new idea of urban management based on the concept of holistic governance and the development of current information technology.
\end{abstract}

Keywords-Holistic governance; Shared cities; urban management

\section{IT IS IMPERATIVE TO STRENGTHEN URBAN GOVERNANCE} RESEARCH

In recent years, with the rapid development of urbanization in the world, urban governance has become a global problem. According to the United Nations "urbanization report (2010) : in 1750, only about $2 \%$ of the population living in cities around the world, the data of 1800 to around $5 \%$, more than $13 \%$ in 1900 , close to $30 \%$ in 1950 , and in 1980 reached $40 \%$, global urbanization rate more than $50 \%$ in 2009, since the data still showed a trend of rising. According to published in May 2016, the United Nations world city status report in 2016 pointed out that by the end of 2015 , the resident population of more than 10 million "super city" has increased from 14 to 28, 22 of them are concentrated in Latin America, Asia and Africa. [1] China's unique development path leads to faster and more rapid urbanization. In 1949, China's urbanization rate was just over 10\%. In 1978, the rate of urbanization was less than $18 \%$, but by 2000 China's urbanization rate had rocketed to $36 \%$. In 2017, the figure exceeded $58 \%$. It is predicted that urbanization will enter a slow phase when the urbanization rate reaches $70 \%$ (that is, a billion people live in towns).

Cities offer great opportunities and possibilities for mankind, but all kinds of urban problems that accompany the rapid development of cities are also prominently displayed in front of us. Take traffic for example, in the first quarter of 2016 China's congested city ranking of the top 20 cities almost covers all the major cities, and congestion of other cities are also close to scale even in a short period of time could enter megacities procession of regional central cities. [3] it is important to stress that not the larger the size of the population is conducive to the social governance of the city, and how to solve these urban problems is the first problem that the city managers need to solve urgently.

\section{HOLISTIC GOVERNANCE: THE MAIN PATH OF URBAN GOVERNANCE \\ Urban governance is a systematic and complete system.} With the expansion of the population scale, the urban social structure has been differentiated, and the interests and interests of the city have become more diversified. In this case, it is easy to devote more energy and resources to the governance of those outstanding issues, and less attention to those areas which have little relation with the performance of political achievements, which can easily generate unreasonable allocation of public resources, resulting in "fragmentation" in the process of urban social governance.

A. theoretical basis of holistic governance.

Holistic governance theory arose in the UK, it emphasizes the value concept of integrity, guided by the demands of citizens, through the coordination and integration of harmony as a governance mechanism, make up for the traditional bureaucracy and the defect of the new public management theory, provides the omni-directional, cooperatives, seamless service supply, build the integrity system of government. [13] (p22-29) In terms of governance capability, holistic governance is conducive to enhancing urban governance. Hicks, holistic governance theory, put forward: holistic governance theory in order to satisfy the demands of citizens as the dominant idea, the integration of public resources to tackle the problem of citizens concerned about most to effectively respond to citizens' demand ". Holistic governance theory focuses on the integrity of the internal institutions and government departments, agencies through the function of similar or complementary function organically integrate and construct the governance structure of the service oriented, so as to create a "compact type" model of urban management. In terms of governance process, holistic governance relies on the joint participation of various parties. It argues that cooperation 
between the public and private sectors, introduced in the process of governance, the concept of "interaction" between the public and private sectors to replace traditional bureaucracy in the era of "public sector" and the new public management in the age of "private sector-led" concept, to encourage the market main body and social organization and social groups and individual participation, realize a flexible supply fault, to eliminate in the process of the urban social governance "fragmentation" of public service. [16]

$B$. the core of holistic governance

1)update the governance concept and adhere to the peopleoriented and cooperative co-governance to achieve universal joint sharing

In the time and space environment of diverse and complex social values, it is necessary to renew the concept of social governance and establish the correct concept of social governance to guide practical activities. At government level, it is necessary to establish "people-oriented, public interest supreme" governing idea, and the governance concept into urban social governance in channels and collaterals, multiple subject establishment and other administrative departments and other cooperation "rightist" governing idea of value.

2) adhere to the core of citizens' needs and public interests, and create a ruling culture of "co-governance and common responsibility"

"Work" is to build a national work sharing an important ideological basis of social governance structure, especially in large urban social public security problem or ecological management, and other fields, cooperation should be plural results has preliminarily revealed. And cooperation "rightist" hicks and scholars put forward the important concept in the theory of holistic governance, he advocates need to pay attention to and responsibilities within the organization trust relationship matching, timely respond to the demands of the public interest, in order to avoid the extra large city will appear in the process of social governance of public interests and responsibility "segmented fragmentation" phenomenon.

C. main practices of holistic governance

The holistic governance theory holds that the integration and optimization of governance structure is mainly the integration of governmental organization structure and form. Organizational structure, power structure of social governance structure and system structure of social governance elements such as scientific and reasonable collocation and arrangement, is conducive to enhance the capacity of social governance, security stability and sustainability of social governance process.

1) organizational structure: transformation from pyramid to flat structure to realize continuous optimization of organizational structure

Because traditional "pyramid" organization structure "accrual resources allocation is unreasonable, the longitudinal administrative chain is too long," the structure of the phenomenon of fragmentation, fuzzy lead to power and responsibility, with the administrative department for has hampered the types of total amount, scope and share data.
Therefore, the government should use modern information technology to promote administrative system transformation, fully exert the advantage of information technology, through large data should be used, in order to break through the traditional hierarchical constraint, makes some bureaucratic institutions intermediary function abate, make the operation of the power of the government and the information works more efficient. On the one hand, lateral changes can be carried out across regional and specialized regions to expand the scope and scope of government internal management and reduce the number of functional departments. Longitudinal change on the other hand can take implementation across levels of governance as a whole, from the pyramid to flat organization structure, between the levels of leapfrogging vertical organization, shorten the distance between the administrative hierarchy, implementation and governance organization structure optimization.

2) power structure: change from centralization to decentralization power, and the right balance of power of real governance body

Promoting the modernization of urban management system and management ability, compose built the work sharing the structure of social governance, not only to achieve the optimization of organizational structure, but also to realize the adjustment of power structure, to achieve the power sharing. On the one hand, it should take effective measures to compress the vertical power structure chain and accelerate the transition of power structure from centralized to flat power. Namely according to the principle of "flat, fine Jane, efficiency", through two levels decrease in the neighborhood and community and function integration, put more administrative power in place, reach the power balance of the vertical upward, to increase the response of local governments and independent. On the transverse distribution of power, on the other hand, in the setting of functional departments, should be the main job of the various functional departments assume responsibility, as well as the work of their should take on the task, service category and nuclear test standards, shape into more of the nature of work force and play "city - street (big club area)" or "area - the streets (community)" power structure. Therefore, through the power of megacities deep pattern reform, eliminate power structure on the root of this "fragmentation", for megacities between different governance body in the process of social governance power structure of the competition and cooperation to lay the good foundation, realize the appropriate checks and balances of power, to adapt to the social transformation and the change of external environment.

3) institutional structure: change from single to diversified system, and effective supply of the system of governance.

In the process of urban social governance, various government departments from the perspective of interests of various since, according to the characteristics of its own department formulate relevant rules and regulations, and no other functions or governance went up from the overall consideration the interests of the main body, make the whole 
system becomes simplified and lack of sample and more unity, caused the entire urban governance structure to present "fragmentation" distribution. Therefore, it is necessary to construct effective institutional guarantee to improve the systematization and diversification of urban social governance. Side surface, should be carefully combing with the various specifications of responsibility of the functional departments, between the governance body in the process of urban community governance information gap flux method, process and so on content, fixed in the form of laws and regulations, and form a pattern of institutionalized collaborative governance, for the market, the social power, heavy citizen participation in urban social management system of the reserved more supply of space. On the other hand, it is necessary to establish the mechanism of urban governance. Encourage social all kinds of management main body to actively participate in city management, through build effective configuration of power and responsibility of social governance mechanism, the social equal consultations on words mechanism, social benefit balanced integration mechanism to deal with the contradiction between the governance body, realize the megacities collaborative governance of the society. Because of this, in the process of promoting the modernization of urban governance, to clarify each kind of main body position in the management of urban modernization management system, clear responsibility and authority of each since and for all kinds of the governance body to provide equal opportunity to participate in urban social governance, give it to a valid interest expression way, in order to better activate all kinds of social governance body in full public service and to realize the function of social governance.

\section{SHARED CITIES: NEW IDEAS FOR INNOVATIVE URBAN DEVELOPMENT}

A. the concept and connotation of Shared cities

From the perspective of social development, the definition of "Shared city" can be defined as a communist social city where people live and work in peace and contentment, and share productive achievements and other legitimate rights and interests. From the perspective of the urban construction of "Shared city" can be defined as: based on the unit community construction, government guide and residents autonomy management as the means, with convenient transportation, information communication is smooth, extensive public participation, for the purpose of jointly build community center city. Urban community is the foundation and source power of "Shared city" construction, and the advantages and disadvantages of urban community construction may affect the development of the whole city.

$B$. it is the core of information technology to realize integrated and refined governance

The holistic governance theory attaches great importance to the use of coordination, integration and combination in the process of social governance, and encourages the use of information network technology to provide the public with seamless public services. With modern information technology is widely spread and development, many cities government departments are using the network information technology "online office", which to some extent, improve the government efficiency. Therefore, by using advanced information technology can integrate the power of crosssectoral, cross-regional and resources, realize information sharing and utilization, to a certain extent, effectively improve social governance in the process of "responsibilities and resource configuration is not reasonable, the longitudinal power levels:" the organizational structure of the relationship. To set up a "Shared city", we should first rationalize the management system, and give full play to the subjective initiative of government agencies and residents. City managers should perfect their own institutions and establish a platform for direct communication with the public. And autonomous management organization dominated by citizens, such as the residents' committee or the owners' committee, etc.), the autonomous management organization can represent residents say, let the citizens in the city have more say in the development and community construction, so as to get feeling, sense of identity and belonging.

Information technology as the core, to coordinate urban social governance through large data, make the data become important decision basis of government management society, can make the city more fine social governance process, thereby improving the effect of social governance, and can largely reduce unnecessary management link, reduce administrative costs.

C. the main ways to build a Shared city

1) information network sharing

To build a Shared city, we must first realize the sharing of information network. The sharing of information network enables citizens to better participate in urban development and community construction, which is an indispensable part of the construction of "Shared city". It is not a simple information exchange or network coverage, but a network technology as the carrier, based on big data, community residents as an individual information sharing platform. The public can obtain the latest policy, economic and cultural information on the Shared platform and fulfill the obligations of citizens. We can also exchange and share information with each other, so as to realize mutual communication among citizens and enhance the community's neighborhood feelings.

\section{2) sharing of transportation network.}

Currently, China is vigorously promoting the use of public transport such as bicycles and Shared cars, promoting green travel and healthy travel. On the one hand... . This has greatly reduced the inconvenience of community residents to travel, reduced the use frequency of private cars, and has great significance for urban development and construction.

3) share of urban management.

Integration and intensification is the development direction of urban governance, governance in city grid, the information into a gripper, and for the city residents to share management concepts and ideas, can better three main body, 
government, society and citizens as a whole to clarify the "who is who, who to treat and cure and treat" three aspects of problems, to further encourage people through a variety of ways to participate in urban construction management work, realize the city construction and management, share together.

Governance is the basis of city, urban governance is the core of "people", the construction of city "sharing", "wisdom city" is the effective means to solve the problem of city, is also a kind of brand-new concept of city development, but also a trend for the future development of the city. Comprehensive use of economic, administrative, legal, technological, cultural and other means; To build a city governance system with clear authority and responsibility, service first, management optimization, law enforcement, and safety and order; And build, work, sharing the new pattern of city governance, is promoting the modernization of urban management system and management ability, solve the good life is people's increasing needs and inadequate imbalance between the development of an important way of contradictions.

\section{REFERENCES}

[1] UN-HABITAT.World Cities Report 2016: Urbanization and Development - Emerging Futures[M].2016-05-24. (In Chinese)

[2] Perri, Diana Leat, Kimberly Seltzer \& Gerry Stoker.Towards holistic governance: The new reform agenda[M]. London: Palgrave Press, 2002.

[3] Fukuyama, Francis. What is Governance?[J].Governance, 2013, 26(3).

[4] ZhuQianwei.From new public management to holistic governance. [J]. Chinese Public Administration,2008,(10). (In Chinese)

[5] LiXiang, SunShuqiu. From fragmentation to wholeness: the road of modernization of social governance in China's megacities..Hubei Social Sciences[J]. 2018,(01). (In Chinese)

[6] LiuBoqi.To build a "Shared city" and build a high-quality community -an alternative perspective to explore the innovation of regional and urban governance[A].INTELLIGENT CITY.2018. (In Chinese)

[7] WangYongjian,WangBigang.Explore the new pattern of urban governance of work sharing[A].PEOPLE'STRIBUNE.2017-12. (In Chinese) 